\title{
Hidradenoma Papilliferum of the Anus: A Report of 2 Cases and Review of the Literature
}

\author{
Guh Jung Seo ${ }^{1}$, Ju Heon $\mathrm{Seo}^{2}$, Kyung Jin $\mathrm{Cho}^{3}$, Hyung-Suk Cho ${ }^{1}$ \\ ${ }^{1}$ Dae Han Surgical Clinic, Gwangju; ${ }^{2}$ Geochang International School, Geochang; ${ }^{3}$ Seoul Song Do Hospital, Seoul, Korea
}

Hidradenoma papilliferum is a rare benign cystic tumor that originates from apocrine glands or anogenital mammary glands. Here, we describe 2 cases of hidradenoma papilliferum of the anus. Two female patients aged 39 and 35 presented with perianal masses with hemorrhoids. The patients underwent hemorrhoidectomy and excision of the lesion. Histopathology confirmed the masses as hidradenoma papilliferum. The postoperative course was uneventful for both patients, and there were no recurrences after 18 and 12 months of follow-up, respectively. Proctologists should consider hidradenoma papilliferum in their differential diagnosis of benign anal tumors. Surgical excision is necessary for diagnosis and treatment of hidradenoma papilliferum.

Keywords: Hidradenoma papilliferum, Benign tumor, Anus, Hemorrhoid

\section{INTRODUCTION}

Hidradenoma papilliferum, also known as papillary hidradenoma, is a rare type of benign neoplasm that originates from the apocrine glands or anogenital mammary glands $[1,2]$. Hidradenoma papilliferum occurs almost exclusively in middle-aged women [3] and presents as a solitary, circumscribed nodule approximately $1 \mathrm{~cm}$ in diameter that may resemble hemorrhoids [4]. Hidradenoma papilliferum lesions are usually asymptomatic, but may be associated with itching, pain, and bleeding or discharge, especially if there is ulceration of the lesion [5]. Here, we describe 2 cases of hidradenoma papilliferum of the anus. To the best of our knowledge, this is the first such report of this disease in Korea.

Received: July 12, 2018 - Accepted: August 3, 2018

Correspondence to: Guh Jung Seo, M.D.

Department of Surgery, Dae Han Surgical Clinic, 41 Bungmun-daero,

Buk-gu, Gwangju 61261, Korea

Tel: +82-62-527-7500, Fax: +82-62-527-7501

E-mail: gs-jjang@hanmail.net

ORCID code: https://orcid.org/0000-0001-7861-6946

- This study was presented as a poster presentation at the ASCRS Annual

Scientific Meeting, May 19-23, 2018, Nashville, Tennessee.

(C) 2019 The Korean Society of Coloproctology

This is an open-access article distributed under the terms of the Creative Commons Attribution NonCommercial License (http://creativecommons.org/licenses/by-nc/4.0) which permits unrestricted non-

commercial use, distribution, and reproduction in any medium, provided the original work is properly cited.

\section{CASE REPORTS}

\section{Case 1}

A 39-year-old female presented to our clinic with anal pain and anal protrusion during defecation. Her past medical history and family history were unremarkable. On physical examination, an approximately 1 -cm-sized, well-circumscribed, umbilicated, reddish nodule with prolapsed hemorrhoids was observed on the anus (Fig. 1A). Laboratory tests including white blood cell count, hemoglobin level, platelet count, alanine aminotransferase, and aspartate transaminase were within normal limits. Viral markers for hepatitis B and serologic studies of an immunocompromised state were all negative. Anoscopy showed multiple internal hemorrhoids. Endoanal ultrasound showed normal findings with no evidence of abscess or fistula. The patient underwent hemorrhoidectomy and excisional biopsy of the mass under caudal block. The patient's postoperative course was uneventful and she was discharged on postoperative day 3. No recurrence was observed after 18 months of follow-up.

\section{Case 2}

A 35-year-old female visited our clinic with a history of anal bleeding and mass. She had a history of cesarean delivery, but her other personal and familiar medical history was unremarkable. On physical examination, a round $0.8-\mathrm{cm}$ size mass on the anus was observed, which appeared as a well-marginated and ulcerated 


\section{Coloproctology Guh Jung Seo, et al.}

red nodule with touch bleeding (Fig. 1B). Routine blood tests were within normal limits. Anoscopy was nonspecific except for internal hemorrhoids. Endoanal ultrasound showed normal findings with no evidence of abscess or fistula. The patient underwent hemorrhoidectomy and excisional biopsy of the lesion under caudal block and had an uneventful recovery. The patient was discharged on postoperative day 3 , and she showed no evidence of recurrence after 12 months of follow-up.

Histopathological examination of the 2 cases revealed a papillary proliferation of a biphasic cell pattern consisting of an inner layer of eosinophilic columnar cells and an outer layer of cuboidal cells without atypia or mitotic figures (Fig. 2). These finding were consistent with hidradenoma papilliferum.

Written informed consent was obtained from both patients for publication of this case report and accompanying images. This study was approved by the electronic Institutional Review Board of the Korea National Institute for Bioethics Policy (KoNIBP P01201807-21-009).

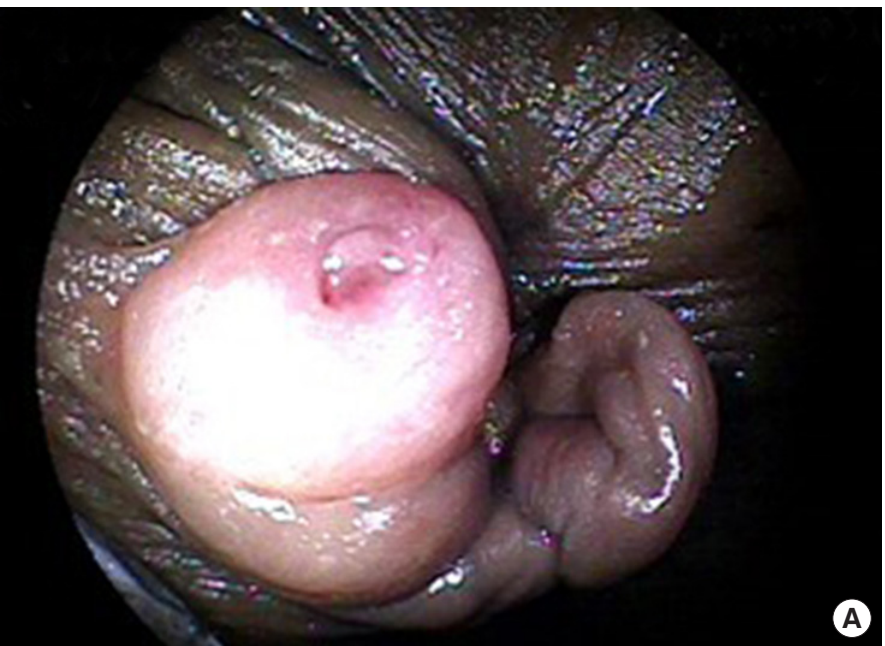

\section{DISCUSSION}

Hidradenoma papilliferum is a rare benign adnexal neoplasm that involves the anogenital area, particularly the vulva or perianal region, and most commonly affects middle-aged women [1-4]. Hidradenoma papilliferum lesions typically appear as asymptomatic, slow-growing, solitary nodules, and are usually less than 1 $\mathrm{cm}$ in diameter $[4,5]$. However, hidradenoma papilliferum may sometimes present with bleeding, pain, pruritus, and ulceration. In the 2 cases described in this report, the lesions presented as symptomatic ulcerated nodules with diameters of $1 \mathrm{~cm}$ and 0.8 $\mathrm{cm}$, respectively. Larger lesions have been reported in the literature. For example, Handa et al. [6] reported a case of a large ulcerated hidradenoma papilliferum up to $4 \mathrm{~cm}$ in diameter.

The etiology of hidradenoma papilliferum is unclear. Hidradenoma papilliferum occurs almost exclusively in the female anogenital area; however, there have been a few isolated reports of perianal hidradenoma papilliferum in male patients $[7,8]$. Hidradenoma papilliferum tumors were previously believed to orig-

Fig. 1. (A, B) Two cases of hidradenoma papilliferum of the anus.
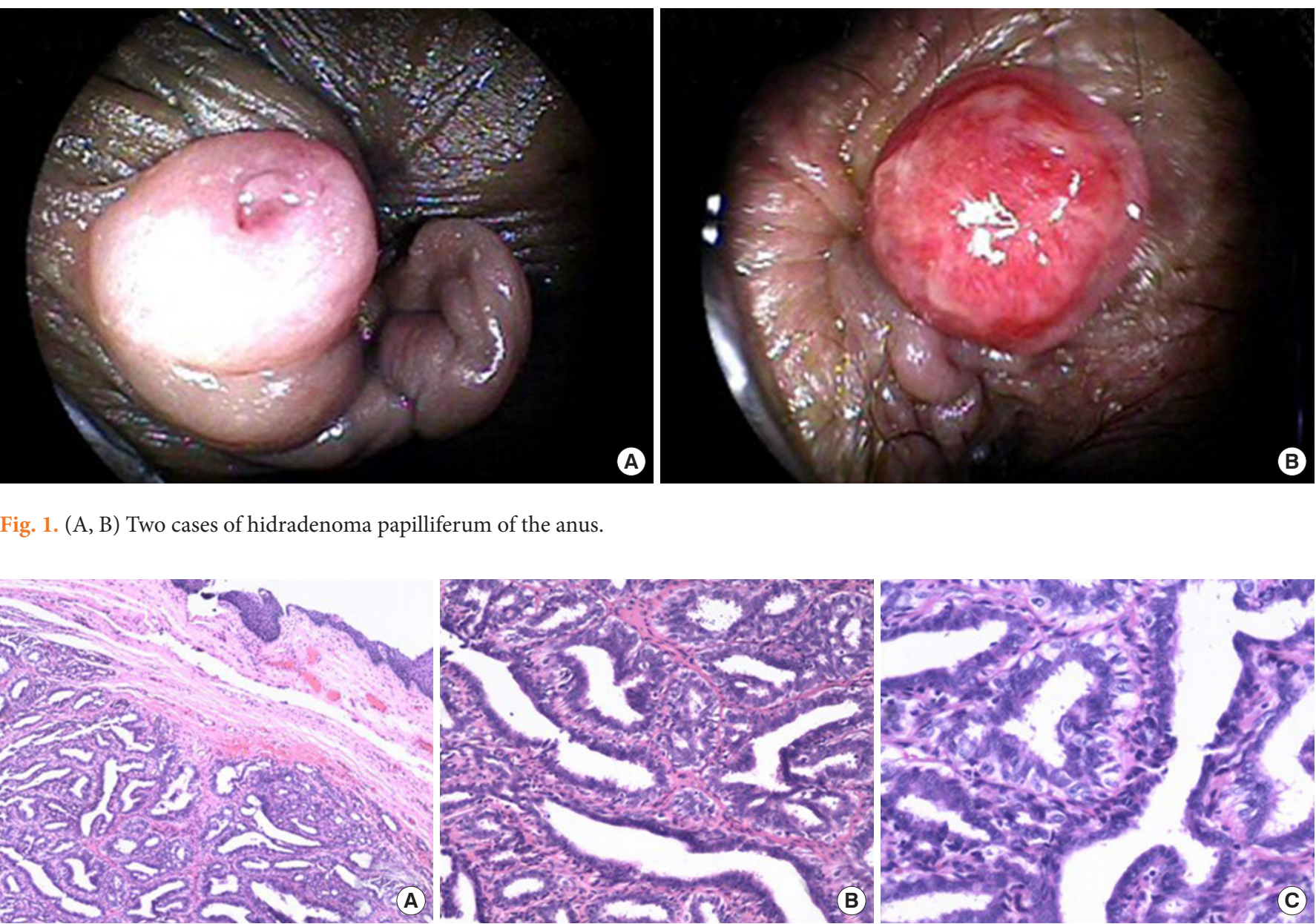

Fig. 2. Microscopic findings of hidradenoma papilliferum (H\&E: A, $\times 40 ; B, \times 100 ; C ; \times 200)$. 
inate from apocrine glands; however, anogenital mammary-like glands have recently been investigated as a potential source [9]. In support of this possibility, mammary-like glands have been documented in several nonanogenital areas such as the ears, face, chest, and scalp [10], and hidradenoma papilliferum tumors do rarely occur in nonanogenital areas, where they are referred to as ectopic hidradenoma papilliferum. The most common site of ectopic hidradenoma papilliferum is the head and neck [10], and in contrast to hidradenoma papilliferum, the incidence of ectopic hidradenoma papilliferum is nearly equal between men and women [10].

There have been several reports of hidradenoma papilliferum of the anus similar to the cases we described $[3,6,7]$; however, most were excised without a clear diagnosis. As a result, there are relatively few images of hidradenoma papilliferum tumors in the literature. Thus, our documentation of the appearance of hidradenoma papilliferum of the anus will be useful to others who encounter this tumor.

The histologic findings of the lesions described in our study revealed a papillary proliferation with dual cell layers comprising inner eosinophilic columnar cells and outer cuboidal cells, consistent with previous reports [7]. Although we did not perform immunohistochemical staining, tumor cells are often immunoreactive for steroid receptors. Importantly, Offidani and Campanati [11] suggested that immunohistochemical analysis for estrogen receptor and progesterone receptor may be reliable markers for distinguishing female anogenital glands from conventional sweat glands.

The overall prognosis for hidradenoma papilliferum is good. Local excision is the treatment of choice regardless of location and size. Tumor recurrence is unusual and is typically attributed to incomplete excision of the primary tumor [5]. In addition, malignant transformation of hidradenoma papilliferum is rare, but there are a few documented cases [12]. In the 2 patients described in this report, no recurrence was observed during the respective follow-up periods of 18 months and 12 months.

Hidradenoma papilliferum is a benign tumor that requires differentiation from many other diseases such as thrombosed external hemorrhoids, anal abscess, viral warts, and epidermoid carcinoma. Less often, hidradenoma papilliferum may be confused with sebaceous cysts, lipomas, or neurofibromas. In cases of associated pigmentation, hidradenoma papilliferum may also be confused with anal endometriosis, angioma, or melanoma of the anogenital area $[3,7]$.

In conclusion, we report 2 cases of hidradenoma papilliferum of the anus. Proctologists should consider the possibility of hidrade- noma papilliferum in their differential diagnosis of benign anal tumors. Surgical excision is necessary for the diagnosis and treatment of hidradenoma papilliferum.

\section{CONFLICT OF INTEREST}

No potential conflict of interest relevant to this article was reported.

\section{REFERENCES}

1. Cunningham JA, Hardy J. Hidradenomas of the vulva; report of four cases with an evaluation of them in the light of analogous breast lesions. South Surg 1947;13:831-8.

2. van der Putte SC. Mammary-like glands of the vulva and their disorders. Int J Gynecol Pathol 1994;13:150-60.

3. Daniel F, Mahmoudi A, de Parades V, Fléjou JF, Atienza P. An uncommon perianal nodule: hidradenoma papilliferum. Gastroenterol Clin Biol 2007;31:166-8.

4. Meeker JH, Neubecker RD, Helwig EB. Hidradenoma papilliferum. Am J Clin Pathol 1962;37:182-95.

5. Kim YJ, Lee JW, Choi SJ, Kim SJ, Kim YJ, Jeon YS, et al. Ectopic hidradenoma papilliferum of the breast: ultrasound finding. J Breast Cancer 2011;14:153-5.

6. Handa Y, Yamanaka N, Inagaki H, Tomita Y. Large ulcerated perianal hidradenoma papilliferum in a young female. Dermatol Surg 2003;29:790-2.

7. Huddleston MK, Jenkins CP, Nelson EC. Hidradenoma papilliferum: a case report of an uncommon perianal lesion. Am Surg 2016;82:E43-4.

8. Loane J, Kealy WF, Mulcahy G. Perianal hidradenoma papilliferum occurring in a male: a case report. Ir J Med Sci 1998;167: 26-7.

9. Kazakov DV, Spagnolo DV, Kacerovska D, Michal M. Lesions of anogenital mammary-like glands: an update. Adv Anat Pathol 2011;18:1-28

10. Vang R, Cohen PR. Ectopic hidradenoma papilliferum: a case report and review of the literature. J Am Acad Dermatol 1999;41: 115-8.

11. Offidani A, Campanati A. Papillary hidradenoma: immunohistochemical analysis of steroid receptor profile with a focus on apocrine differentiation. J Clin Pathol 1999;52:829-32.

12. Vazmitel M, Spagnolo DV, Nemcova J, Michal M, Kazakov DV. Hidradenoma papilliferum with a ductal carcinoma in situ component: case report and review of the literature. Am J Dermatopathol 2008;30:392-4. 